\title{
Testing the effects of ethinylestradiol and of an environmentally relevant mixture of xenoestrogens as found in the Douro River (Portugal) on the maturation of fish gonads-A stereological study using the zebrafish (Danio rerio) as model
}

\author{
Paula Silva ${ }^{\mathrm{a}, \mathrm{b}}$, Maria J. Rocha ${ }^{\mathrm{b}, \mathrm{c}}$, Catarina Cruzeiro $^{\mathrm{b}}$, Fernanda Malhão ${ }^{\mathrm{a}}$, Bruno Reis ${ }^{\mathrm{b}}$, Ralph Urbatzka $^{\mathrm{b}}$, \\ Rogério A.F. Monteiro ${ }^{\mathrm{a}, \mathrm{b}}$, Eduardo Rocha ${ }^{\mathrm{a}, \mathrm{b}, *}$ \\ a Laboratory of Histology and Embryology, Institute of Biomedical Sciences Abel Salazar (ICBAS), University of Porto (U.Porto), Portugal

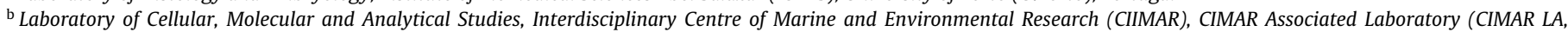 \\ University of Porto (U.Porto), Portugal \\ c Superior Institute of Health Sciences-North (ISCS-N), CESPU, Gandra, Paredes, Portugal
}

\section{A R T I C L E I N F O}

\section{Article history:}

Received 7 February 2012

Received in revised form 1 July 2012

Accepted 4 July 2012

\section{Keywords:}

Zebrafish

Estrogens

Testis

Ovary

Stereology

Endocrine disruptors

\begin{abstract}
A B S T R A C T
In natural environments fish populations are exposed to many potential xenoestrogens, whereby understanding the impacts of mixtures continue to be of great interest. The main objective of this study was, therefore, to understand whether and how an environmentally relevant mixture of xenoestrogens found in the Douro River estuary can disrupt the normal gametogenesis in fish. For this purpose, adult zebrafish of both sexes were exposed for 21 days to an environmental mixture (MIX) of 11 xenoestrogens from diverse sources. A $100 \mathrm{ng} / \mathrm{L}$ ethinylestradiol (EE2) positive control was added. A quantitative (stereological) analysis with systematic sampling was made in the gonads, and using light microscopy both the relative and the absolute volumes of the gametogenic stages were estimated. Data point that the EE2 stimulus induced changes in structural compartments; with decreasing trends for the advanced maturation stages both in males and females. There was also a trend for a greater amount of interstitial tissue in males. Along with an interstitial fibrosis increase detected, the presence of a proteinaceous fluid was observed in both sexes and experimental groups (EE2 and MIX). Other histopathologic alterations were observed in the EE2 female group, such as the presence of foci of granulomatous inflammation and follicular mineralization in the germinal parenchyma and luminal areas. The most interesting finding of this study was that the exposure to the MIX caused a decrease of the relative volume of spermatozoa in zebrafish. This kind of estrogenic effect has not earlier been structurally quantified in such a fine detail with unbiased stereology in fish gonads. Despite the ultimate consequences of such disruptions being unknown, it could be logically argued that reduction or slowing-down of the appearance of the most mature cohorts and/or eventual interstitial fibrosis and other pathologic changes can adversely affect breeding. The findings add further explanatory bases for understanding the negative impacts of xenoestrogens.
\end{abstract}

(c) 2012 Elsevier B.V. All rights reserved.

\section{Introduction}

Over the past twenty years, considerable and growing attention has been given to the fact that chemical compounds can be biologically active by disrupting the normal functions of the endocrine systems of animals. Those substances, called endocrine disrupting chemicals (EDCs), are widespread throughout the aquatic ecosystems and their effects and modes of action have been documented

\footnotetext{
* Corresponding author at: Laboratory of Histology and Embryology, ICBAS - Institute of Biomedical Sciences Abel Salazar, Rua de Jorge Viterbo Ferreira 228, 4050-313 Porto, Portugal. Tel.: +351220 428000 .

E-mail address: erocha@icbas.up.pt (E. Rocha).
}

(Depledge and Billinghurst, 1999; Porte et al., 2006; Segner et al., 2003). Aquatic species are exposed to EDCs through a variety of sources, but wastewater is the main source of EDCs such as those that mimic the effects of natural estrogens (xenoestrogens) (Falconer et al., 2006; Kolpin et al., 2002; Metcalfe et al., 2001; Ying et al., 2002).

Under laboratory conditions, xenoestrogens have been reported to cause a variety of effects in fish reproduction such as changes in plasma hormone concentrations (Khan and Thomas, 1998), gonadal size (Ashfield et al., 1998; Gray and Metcalfe, 1997; Jobling et al., 1996), development of intersex gonads (ovotestis) (Gray and Metcalfe, 1997) and induction of the female yolk precursor protein, vitellogenin (VTG) (Jobling et al., 1996). Although there has been an increased effort to understand the mechanisms by which 
xenoestrogens exert final effects, fundamental doubts still remain, such as the impact on the kinetics of gametogenesis. Several studies suggest that exposure to xenoestrogens may cause suppression of gametogenesis in both male and female fish (Blázquez et al., 1998; Christiansen et al., 1998; Drèze et al., 2000; Gimeno et al., 1998; Papoulias et al., 2000; Piferrer and Donaldson, 1992; Tanaka and Grizzle, 2002; Van Den Belt et al., 2002; Weber et al., 2003). All those histological investigations involved a tissue microscopic analysis, which resulted in visual qualitative descriptions and/or semi-quantitative data or in quantifications by two-dimensional measurements, which are to be avoided as they are well-known now to suffer from uncontrolled biases (Howard and Reed, 2005). The application of stereology to such issues, however, can result in unbiased quantitative data sets, and thus could be a far more adequate approach for investigating the impact of xenoestrogen exposure on gametogenesis kinetics. Most research on effects of xenoestrogens on fish, done under laboratory conditions, has focused primarily on exposure to single chemicals, despite the fact that the aquatic environment receives influxes of different chemicals. This wide range of xenoestrogens in the aquatic environment highlights the importance of improving our understanding of the combinatory effects of the chemicals, at least in model organisms. The existence of interactive effects implies that the estrogenic effect of a mixture may somehow deviate from what would be expected of each single agent acting on its own.

In view of the above, we wanted to study whether and how one environmentally relevant mixture of xenoestrogens as found in the Douro River (Rocha et al., 2011) could disrupt the normal cellular kinetics of both spermatogenesis and oogenesis in fish. As a positive control we exposed fish to $17 \alpha$-ethinylestradiol (EE2) at a high concentration $(100 \mathrm{ng} / \mathrm{L})$ to promote the appearance of more marked effects that could serve as reference. Another study with the same experimental design, and testing both the same MIX and $\mathrm{EE} 2$, disclosed changes in sex steroidogenesis at the molecular level and a different behavior of the MIX and EE2 on specific transcription factors in the zebrafish brain (Urbatzka et al., 2012). Herein, we specifically tested the hypothesis that such exposures could evoke volume changes in different germ cells, detectable only with stereological tools. The zebrafish (Danio rerio, Hamilton) was chosen because it has been recommended for assessing effects of toxicants on development and reproduction (Andersen et al., 2000; Segner et al., 2003).

\section{Material and methods}

\subsection{Test compounds and their nominal and measured concentrations}

Stock solutions of EE2 (Sigma-Aldrich) and the Douro's environmental mixture (MIX) were prepared in ethanol at the beginning of the exposure. The xenoestrogens that composed the mixture and their chosen nominal concentrations were based on what was found by chemical screening in the Douro River estuary (Rocha et al., 2011) and are shown on Table 1. This also provides the measured concentrations in the aquaria (analytical details below). Measured concentrations were similar to the nominal ones, and variations were minimal. The estrogenic potency of the MIX was estimated to be $20.73 \mathrm{ng} / \mathrm{L}$ EE2-equivalents (Urbatzka et al., 2012). As the focus herein was the MIX, the estrogenic potency of each chemical was not evaluated. Also, it is well known that they differ in potencies (Laws et al., 2000; Gutendorf and Westendorf, 2001; Preuss et al., 2006).

During the trials, the stock solutions were diluted, daily, in water, and used for renewal of the test solutions in the aquaria. Ethanol (p.a. grade) was used as vehicle, and its final concentration
Table 1

Xenoestrogens in the Douro's environmental mixture (MIX) used in the exposure assay. Measured concentration is a pooled value ( \pm standard deviation) between times $0 \mathrm{~h}$ (just after water renewal) and $24 \mathrm{~h}$ (just before the next water renewal).

\begin{tabular}{lcr}
\hline Xenoestrogen & $\begin{array}{l}\text { Nominal } \\
\text { Concentration } \\
\text { (ng/L) }\end{array}$ & $\begin{array}{l}\text { Measured } \\
\text { Concentration } \\
\text { (ng/L) }\end{array}$ \\
\hline Estrone (E1) & 2.8 & $2.8 \pm 0.0$ \\
$17 \beta$-Estradiol (E2) & 20.0 & $20.0 \pm 0.0$ \\
$17 \alpha$-Ethinylestradiol (EE2) & 4.3 & $4.2 \pm 0.2$ \\
4-t-Octylphenol (4-t-OP) & 17.9 & $16.9 \pm 1.5$ \\
4-n-Octylphenol (4-n-OP) & 6.0 & $6.0 \pm 0.0$ \\
Bisphenol A (BPA) & 25.7 & $25.7 \pm 0.0$ \\
4-Octylphenol monoethoxylate (OP1EO) & 10.5 & $10,0 \pm 0.7$ \\
4-Octylphenol diethoxylate (OP2EO) & 16.0 & $16.0 \pm 0.0$ \\
4-Nonylphenol monoethoxylate (NP1EO) & 21.9 & $21.9 \pm 0.0$ \\
4-Nonylphenol diethoxylate (NP2EO) & 1608.0 & $1608.0 \pm 0.0$ \\
4-n-Nonylphenol (4-n-NP) & 3.5 & $3.1 \pm 0.6$ \\
\hline
\end{tabular}

in the aquaria, in both treatment and controls, was $\approx 0.001 \%$. This was the minimum amount necessary to dissolve the chemicals of the mixture. The nominal used concentration was 10 times lower than the maximum solvent concentration recommended by OECD $(100 \mu \mathrm{l} / \mathrm{L})$. Additionally, the concentration used was half the conservative safe-guard limit of $20 \mu \mathrm{l} / \mathrm{L}$ proposed by Hutchinson et al. (2006), when reviewing acute and chronic effects of carrier solvents in aquatic animals.

Water samples ( $1 \mathrm{~L}$ ) were weekly collected after renewing the test solutions and just before the next renewal from each of the experimental aquaria (see below Section 2.3). These samples were then added with internal deuterated surrogates (E2- $\mathrm{d}_{2}$ and BPA$\mathrm{d}_{16}$ ) and submitted to solid phase extraction (SPE) (Rocha et al., 2010). Briefly, the water samples were loaded onto SPE Oasis HLB ${ }^{\mathrm{TM}}$ (hydrophilic-lipophilic balance) cartridges at a constant flow rate of $5 \mathrm{~mL} / \mathrm{min}$ followed by a washing step of $10 \mathrm{~mL}$ of ultrapure water and methanol (9:1). Cartridges were dried under vacuum for $60 \mathrm{~min}$ and then eluted with $10 \mathrm{~mL}$ of ethyl acetate, at $1 \mathrm{~mL} / \mathrm{min}$. The resulting extracts were evaporated to dryness in a heating block at $40^{\circ} \mathrm{C}$ under a gentle stream of nitrogen and reconstituted in $500 \mu \mathrm{L}$ of anhydrous methanol. Due to the low volatility of the majority of the present compounds, $50 \mu \mathrm{L}$ of each extracted fraction were transferred into GC vials and evaporated to dryness under a gentle nitrogen stream. Fifty $\mu \mathrm{L}$ of pyridine were added to the dry residues which were derivatized by the addition of $50 \mu \mathrm{L}$ of N,O-bis(trimethylsilyl)trifluoroacetamide (BSTFA) added with 1\% trimethylchlorosilane (1\% TMCS). The vials were mixed using a vortex system and heated, in a heating block, for $30 \mathrm{~min}$ at $65^{\circ} \mathrm{C}$. Then each sample was analyzed in a gas chromatograph (Trace GC ultra, Thermo Finnigan Electron Corporation) coupled with an ion trap mass spectrometer (Thermo Scientific ITQ ${ }^{\mathrm{TM}} 1100$ GC-MS $^{n}$ ), an autosampler (Thermo Scientific TriPlus ${ }^{\mathrm{TM}}$ ) and a TR5MS capillary column ( $30 \mathrm{~m} \times 0.25 \mathrm{~mm}$ i.d., $0.25 \mu \mathrm{m}$ film thickness). Helium carrier gas (99.999\% purity) was maintained at a constant flow rate of $1.0 \mathrm{~mL} / \mathrm{min}$ and the column oven temperatures were programmed according to Rocha et al. (2010). Finally, the quantitative analysis was made in a selected ion monitoring mode (SIM) using external calibration. After renewing the test solutions the measured concentrations matched the nominal ones. Immediately before the next renewal the actual concentrations averaged $95 \%$ of the nominal ones, with no detectable variations in most compounds (Table 1).

\subsection{Experimental animals}

Adult zebrafish were obtained from a local specialized dealer. Fish were received at the Interdisciplinary Centre for Marine and Environmental Research (Porto) bioterium and were kept for 4 weeks, separated by sex, in a $600 \mathrm{~L}$ tank with dechlorinated water. 
There was not specific spawning subtract. After the above specified period, the animals were allowed to acclimate to experimental conditions for 15 days. For that purpose and also to induce interfish synchronization, homogeneous groups of zebrafish (16 males and 16 females - to provide a sex ratio of $1: 1)$ were randomly distributed among 6 glass tanks ( $25 \mathrm{~L}$ each), at a temperature of $27 \pm 1^{\circ} \mathrm{C}$. Fish were exposed to a 14 -h light/10-h dark photoperiod. The water oxygen concentration was near air saturation level. Before the experiment, fish were fed ad libitum, twice a day, with dry flake food (Sera vipan ${ }^{\circledR}$ ) and once with artemia nauplii (Artemia salina, Ocean Nutrition).

\subsection{Experimental design}

Fish were exposed to one of the following treatments (two replicates per condition): solvent control (C), $17 \alpha$-ethinylestradiol positive control (EE2) (nominal and measured concentrations of $100 \mathrm{ng} / \mathrm{L}$ ) and Douro's environmental mixture (MIX). The exposure took place in the glass aquaria under semi-static conditions with one daily total renewal of the water, for restoration of the nominal concentrations. To minimize stress, water changes were gently made by slowly siphoning, temperature was always the same, and the animals were exposed to low water levels only for short periods (in the order of seconds). During the experiment, the fish were fed two times a day with the same flake dry food used during the acclimatization period. Measurements of $\mathrm{pH}$, dissolved oxygen, temperature, ammonia and nitrite levels were carried out daily. After 21 days of exposure, each fish was deeply anesthetized by immersion in a bath of 2-phenoxyethanol solution $(0.5 \mathrm{~mL} / \mathrm{L})$ (Sigma-Aldrich) and immediately sacrificed by cutting the spinal cord. For this study, 6 fish per sex and per treatment were analyzed (3 per replica). These fish were unbiasedly selected by a systematic sampling scheme. The remaining fish were sampled for other studies. It is important to point out that within the scope of this study, no differences were found between replicated tanks. After being weighed and measured (total length) the fish were dissected and their gonads were weighed. The gonadosomatic indices (GSI) were calculated as follows:

$\mathrm{GSI}=\frac{\text { (weight of the gonads in } \mathrm{mg} \text { ) }}{\text { (weight of the total body in } \mathrm{mg} \text { ) }} \times 100$.

\subsection{Histological preparation}

Gonads fixed in commercial $4 \%$ buffered formalin (J.T. Baker) were processed for histological examination by light microscopy. After fixation ( $48 \mathrm{~h})$, the tissues were dehydrated through a series of graded ethanol (AGA) solutions (70-99.8\%), cleared in xylene (BDH - Prolabo), and impregnated in paraffin (Merck) in a semi-enclosed benchtop tissue processor (Leica TP 1020). Finally, the tissues were embedded in paraffin in a modular tissue embedding center (Leica EG 1140C). Each gonad was entirely sectioned (Microtome - Leica RM 2155) into thin sections ( $4 \mu \mathrm{m}$ thick). The sections were systematically sampled during sectioning so that at least a minimum of 10 sections per animal were analyzed. For improving section adhesion, the sampled sections were mounted in slides coated with aminopropyltriethoxysilane(APES)(Sigma-Aldrich), and then stained with haematoxylin-eosin before being coversliped.

\subsection{Histological and stereological analysis}

For estimating the relative volume densities of the gonadal structures, a stereological approach was made using an interactive image analysis workstation (CAST-Grid, Olympus, Version 1.6), working with a live-image captured by a color CCD-video camera (Sony). The light microscope (BX50, Olympus) was equipped with a

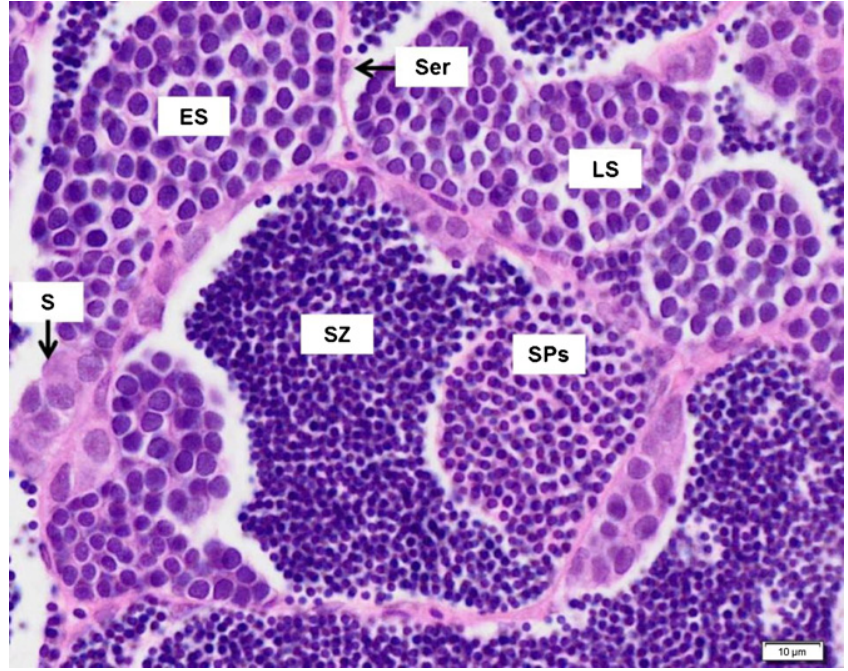

Fig. 1. Different germ cell cysts observed during the spermatogenic process in zebrafish. Ser - Sertoli cell; S - Spermatogonia; ES - Early spermatocytes; LS - Late spermatocytes; SPs - spermatids and SZ - Spermatozoa.

fully-motorized stage (Prior Scientific), thus allowing meander systematic sampling with an ( $x-y$ axis) accuracy of $1 \mu \mathrm{m}$. The meander sampling was controlled by the software.

The volume densities (later expressed in the results as \%) of the gonadal structures $\left[V_{V}\right.$ (structure,gonad)] were estimated by an unbiased, stereological technique based on point-counting by the observer operating the CAST-Grid (Howard and Reed, 2005):

$V_{V}($ structure, gonad $)=\frac{\sum P(\text { structure })}{R \sum P(\text { gonad })}$

where $\sum P($ structure $)$ and $\sum P$ (gonad) correspond to the total number of grid points in a section hitting the structure of interest or its reference space (gonad), respectively, and $R$ is the inverse of the point-ratio used for each particular $V_{V}$ estimation. In males a 1:4 two lattice point-system grid was overlaid on the live videoimage displayed on a $17^{\prime}$ monitor. For the testis and spermatozoa the $1: 1$ point ratio was used. The tighter $1: 4$ point ratio was used for all the other structural compartments. In females a 1:9 two lattice point system grid was used. The $1: 9$ point ratio was used for all the structures with the exception of mature oocyte stage. Pointcounting was made in systematically sampled fields working either with the $100 \times$ (males) or $10 \times$ (females) objective lens, giving the respective final working magnification of the live image in the monitor of $4050 \times$ and $399 \times$, respectively. After pilot trials, the stepwise stage $x-y$ movement was set according to the gonad size in order to count an optimal number of cells per section; the adopted steps varied from 200 to $300 \mu \mathrm{m}$ in males, and from 700 to $950 \mu \mathrm{m}$ in females.

Histological alterations in the testis were evaluated based on the presence of different stages of germ cells, of interstitial tissue and of Sertoli cells. Five testicular populations were identified as follows (Fig. 1): Spermatogonia (the largest of the spermatogenic cells; acidophilic cytoplasm with relatively larger nucleus containing poorly condensed chromatin and one or two compact nucleoli); Early and late spermatocytes (early spermatocytes are larger than late spermatocytes with thread-like or condensed chromatin, respectively, with relatively smaller cytoplasm with no affinity for dye); Spermatids (dense nuclei and narrow rims of eosinophilic cytoplasm) and Spermatozoa (dark, round nuclei and minimal or no apparent cytoplasm). The latter are the smallest spermatogenic cells and they exist as scattered individual cells within the lumen of the anastomosing seminiferous tubules. 

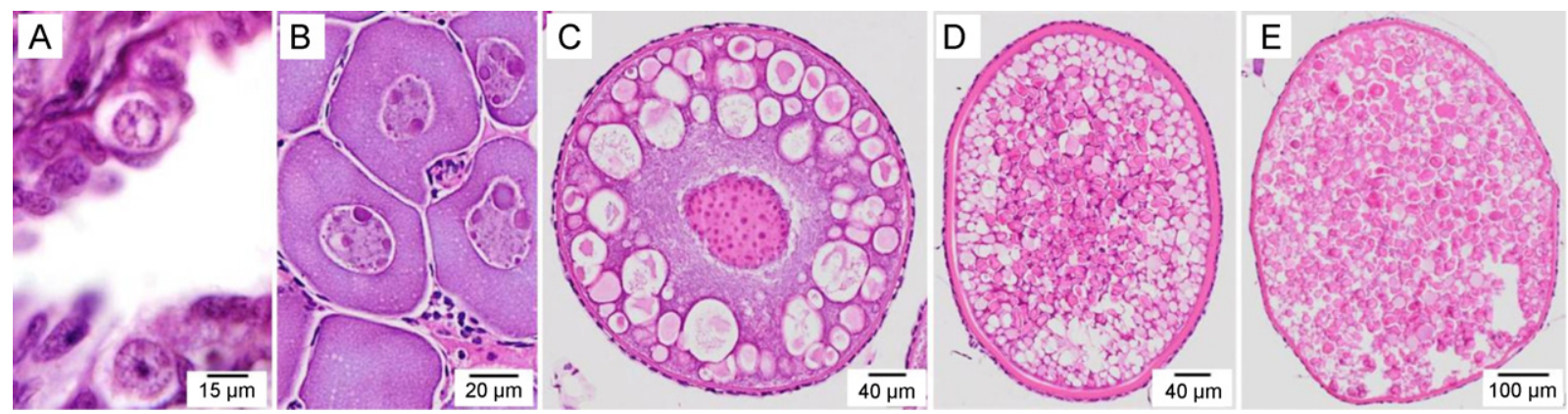

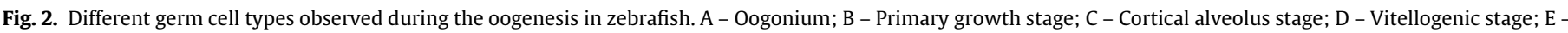
Mature stage.

Five follicular stages of maturation were identified and counted from the ovaries (Fig. 2): Oogonium (high ratio nucleus/cytoplasm; acidophilic nuclear membrane and nucleolus; cytoplasm weakly acidophilic); Primary growth stage (enlarged basophilic cytoplasm; pale nucleus with many nucleoli distributed along the nuclear membrane); Cortical alveolus stage (presence of the cortical alveoli in the cytoplasm, first in the peripheral zone and after in all cytoplasm; irregular nuclei shape with nucleoli attached to inner border of nuclear membrane); Vitellogenic stage (cytoplasm with yolk bodies which are heterogeneous in appearance; migration of the nucleus to the animal pole; zona radiata prominent and granulosa-theca cells easily identified); Mature stage (oocyte filled with yolk bodies; small area occupied by the cytoplasm; oocyte layers folded irregularly). Atretic (degenerated) follicles and interstitial tissue were also counted.

For estimating total volumes, we assumed in this study that the gonadal density was $\approx 1 \mathrm{mg} / \mathrm{mm}^{3}$ both for testis and ovaries, so that the gonad volume $[V($ gonad $)]\left(\mathrm{mm}^{3}\right)$ was deemed herein as equal to the gonad weight $(\mathrm{GW})$. The absolute volumes $\left(\mathrm{mm}^{3}\right)$ of all the gonadal structures considered above were thus estimated based on the formula:

$V($ structure $)=V($ gonad $) V_{V}($ structure,gonad $)$

Both testis and ovary sections were examined under light microscope to investigate the presence of pathological modifications in the gonads. The diagnosis of such changes was done in accordance with the OECD guidelines (OECD, 2009).

\subsection{Statistics}

Data were analyzed using the software Statistica (version 10, StatSoft). The significance level was set at $\alpha=0.05$. All variables were checked for normality and homogeneity of variance by using the Kolmogorov-Smirnov and the Levene tests, respectively. Data were submitted to one-way analysis of variance (ANOVA). After a significant ANOVA, pairs of means were compared by the Newman-Keuls test. In the specific cases where the parametric ANOVA assumptions failed, data were submitted to Kruskal-Wallis test and to Mann-Whitney $U$ non-parametric test. The nonparametric results were alike those of the parametric ANOVA analysis, strengthening the confidence in the significance of the differences.

\section{Results}

\subsection{Biometric parameters}

At the end of experiment the body weight of zebrafish males and females exposed to EE2 was significantly lower than that in the other two groups (Table 2$)$. No significant effects $(p>0.05)$ on total length were observed after 21 days of exposure to any treatment in either sex. The testis and ovary weight followed the same trend as body weight, as a lower value was found in fish exposed to EE2 with no differences between the control and the MIX group observed (Table 2 ). A significant reduction $(p<0.05)$ in GSI was also observed in both zebrafish males and females of the positive control group when compared to the control one. Females exposed to the xenoestrogen mixture, however, presented the highest GSI (Table 2).

\subsection{Histological and stereological analysis}

In accordance with the gonad weights, the absolute volumes of the gonads followed the same trend as the body weight: a decrease in the testis and ovary volumes was only observed in males and females exposed to EE2, respectively (Tables 3 and 4). Histological examination of gonad sections from control and treatment groups revealed normal testicular and ovarian organizational architecture and progression of gametogenesis. Leydig cells could be identified within the stroma, although their positive identification was not consistent. The germ cell types selected for quantification were averaged and represented as a relative volume of the whole testis (Fig. 3) and ovary (Fig. 4). The stereological study revealed a reduction in the absolute volumes of the germ cells in both male and female gonads of fish from the positive control group (Tables 3 and 4). The analysis of the relative volumes of testis cells revealed maturation suppression both with the EE2 and the mixture of xenoestrogens (Fig. 3). The number of spermatozoa decreased with the two treatments, the lower values being observed in the positive control group. The number of spermatids decreased only in males exposed to EE2 (Fig. 3). Both the relative and the absolute volumes of Sertoli cells were similar in all groups

Table 2

Body weight (BW), total length (TL), gonad weight (GW) and gonadosomatic index (GSI) of zebrafish exposed to xenoestrogens for 21 days (solvent control - C; positive control - EE2 and Douro's environmental mixture - MIX).

\begin{tabular}{lllc}
\hline & C & EE2 & MIX \\
\hline Males & & & \\
BW $(\mathrm{g})$ & $0.406 \pm 0.059^{\mathrm{a}}$ & $0.317 \pm 0.033^{\mathrm{b}}$ & $0.427 \pm 0.063^{\mathrm{a}}$ \\
TL $(\mathrm{cm})$ & $3.522 \pm 0.209$ & $3.585 \pm 0.143$ & $3.569 \pm 0.204$ \\
GW $(\mathrm{g})$ & $0.006 \pm 0.001^{\mathrm{a}}$ & $0.003 \pm 0.001^{\mathrm{b}}$ & $0.006 \pm 0.002^{\mathrm{a}}$ \\
GSI & $1.448 \pm 0.166^{\mathrm{a}}$ & $0.938 \pm 0.300^{\mathrm{b}}$ & $1.410 \pm 0.453^{\mathrm{a}}$ \\
FEMALES & & & \\
BW $(\mathrm{g})$ & $0.535 \pm 0.032^{\mathrm{a}}$ & $0.343 \pm 0.096^{\mathrm{b}}$ & $0.497 \pm 0.083^{\mathrm{a}}$ \\
TL $(\mathrm{cm})$ & $3.588 \pm 0.118$ & $3.586 \pm 0.153$ & $3.682 \pm 0.161$ \\
GW $(\mathrm{g})$ & $0.047 \pm 0.006^{\mathrm{a}}$ & $0.010 \pm 0.004^{\mathrm{b}}$ & $0.058 \pm 0.017^{\mathrm{a}}$ \\
GSI & $8.842 \pm 0.874^{\mathrm{a}}$ & $2.887 \pm 1.120^{\mathrm{b}}$ & $11.346 \pm 2.043^{\mathrm{c}}$ \\
\hline
\end{tabular}

Values are presented as mean \pm standard deviation (SD), $n=6 /$ treatment group Means within a row without a common superscript letter differ significantly $(p<0.05)$. Absence of superscript indicates no significant difference between treatments. 
Table 3

Absolute volumes $\left(\mathrm{mm}^{3}\right)$ of the germ cell present in zebrafish testis exposed to xenoestrogens for 21 days (solvent control - C; positive control - EE2 and Douro's environmental mixture - MIX).

\begin{tabular}{llll}
\hline & C & EE2 & MIX \\
\hline Testis & $5.75 \pm 1.49^{\mathrm{a}}$ & $2.93 \pm 0.83^{\mathrm{b}}$ & $5.98 \pm 1.86^{\mathrm{a}}$ \\
Spermatogonia & $0.20 \pm 0.08^{\mathrm{a}}$ & $0.09 \pm 0.08^{\mathrm{b}}$ & $0.22 \pm 0.10^{\mathrm{a}, \mathrm{b}}$ \\
Early spermatocyte & $0.85 \pm 0.36^{\mathrm{a}}$ & $0.44 \pm 0.18^{\mathrm{b}}$ & $1.06 \pm 0.39^{\mathrm{a}}$ \\
Late spermatocyte & $0.59 \pm 0.16^{\mathrm{a}}$ & $0.30 \pm 0.09^{\mathrm{b}}$ & $0.64 \pm 0.32^{\mathrm{a}}$ \\
Spermatid & $0.27 \pm 0.11^{\mathrm{a}}$ & $0.09 \pm 0.06^{\mathrm{b}}$ & $0.27 \pm 0.08^{\mathrm{a}}$ \\
Spermatozoa & $2.28 \pm 0.64^{\mathrm{a}}$ & $0.45 \pm 0.15^{\mathrm{b}}$ & $1.93 \pm 0.52^{\mathrm{a}}$ \\
Lumen & $1.09 \pm 0.33$ & $0.68 \pm 0.27$ & $1.34 \pm 0.64$ \\
Sertoli cells & $0.03 \pm 0.02$ & $0.02 \pm 0.02$ & $0.03 \pm 0.02$ \\
Interstitial tissue & $0.44 \pm 0.11^{\mathrm{a}}$ & $0.87 \pm 0.35^{\mathrm{b}}$ & $0.49 \pm 0.22^{\mathrm{a}}$ \\
\hline
\end{tabular}

Values are presented as mean \pm standard deviation (SD), $n=6 /$ treatment group. Means within a row without a common superscript letter differ significantly $(p<0.05)$. Absence of superscript indicates no significant difference between treatments.

(Table 3 and Fig. 3). Exposure to EE2 also caused suppression of ovarian maturation, inducing ovaries that were mainly composed of follicles at the earliest stages of development (primary growth) and with lower volumes of vitellogenic and of mature follicles (Fig. 4). The xenoestrogen mixture had no statistically significant effect on female gametogenesis (Fig. 4).

The parameter termed "interstitial tissue" includes the connective tissue, blood vessels and all histologic alterations observed, such as the presence of fibrosis, inflammation tissue and proteinaceous fluid. As to the testis, Leydig cells were also included in that structural compartment. In males, the interstitial tissue absolute volume was higher in the EE2 group (Table 3). The corresponding relative volume was higher both in males and in females exposed to EE2 (Figs. 3 and 4). The interstitial fibrosis was the major contributor to this increase in both sexes. Besides fibrosis, the presence of interstitial proteinaceous fluid was the other pathological alteration observed in the testis of $50 \%$ of the males (Fig. 5) and in the ovary of all females (Fig. 6) exposed to EE2. A lowered amount of proteinaceous fluid was also observed in $50 \%$ of the females and
Table 4

Absolute volumes $\left(\mathrm{mm}^{3}\right)$ of the germ cell present in zebrafish ovary exposed to xenoestrogens for 21 days (solvent control - C; positive control - EE2 and Douro's environmental mixture - MIX).

\begin{tabular}{lclc}
\hline & $C$ & EE2 & MIX \\
\hline Ovary & $47.35 \pm 6.18^{\mathrm{a}}$ & $9.92 \pm 4.15^{\mathrm{b}}$ & $57.53 \pm 17.43^{\mathrm{a}}$ \\
Oogonium & $0.08 \pm 0.06$ & $0.10 \pm 0.18$ & $0.12 \pm 0.11$ \\
Primary growth & $7.63 \pm 2.06$ & $5.29 \pm 1.76$ & $8.44 \pm 2.42$ \\
Cortical alveolus & $5.77 \pm 1.99^{\mathrm{a}}$ & $0.76 \pm 0.93^{\mathrm{b}}$ & $4.51 \pm 1.67^{\mathrm{a}}$ \\
Vitellogenic & $13.86 \pm 4.39^{\mathrm{a}}$ & $0.26 \pm 0.55^{\mathrm{b}}$ & $13.42 \pm 8.10^{\mathrm{a}}$ \\
Mature & $11.14 \pm 5.38^{\mathrm{a}}$ & $0.03 \pm 0.06^{\mathrm{b}}$ & $15.60 \pm 7.39^{\mathrm{a}}$ \\
Atretic & $6.19 \pm 3.67^{\mathrm{a}}$ & $0.34 \pm 0.45^{\mathrm{b}}$ & $13.25 \pm 6.19^{\mathrm{a}}$ \\
Interstitial tissue & $2.68 \pm 1.61$ & $3.14 \pm 2.33$ & $2.21 \pm 0.60$ \\
\hline
\end{tabular}

Values are presented as mean \pm standard deviation (SD), $n=6 /$ treatment group. Means within a row without a common superscript letter differ significantly $(p<0.05)$. Absence of superscript indicates no significant difference between treatments.

$50 \%$ of the males of the MIX experimental group. In the ovary of all females exposed to EE2, epithelioid macrophage granulomas were observed (Fig. 6). In 3 of the 6 ovaries analyzed, presumptively mineralized structures were found near those granulomatous inflammation areas (Fig. 6). Those mineralized structures were commonly associated with atretic oocytes under resorption, and for this reason were included in that category (Fig. 4). However, the absolute and relative volumes of the atretic follicles were lower in females exposed to EE2 when compared with control and MIX groups (Table 4 and Fig. 4). No pathological alterations were found in gonads from the control group.

\section{Discussion}

\subsection{Novelty of the study}

To our knowledge, this is the first quantitative histological investigation to evaluate the effects of an environmentally relevant and complex mixture of xenoestrogens on the relative and

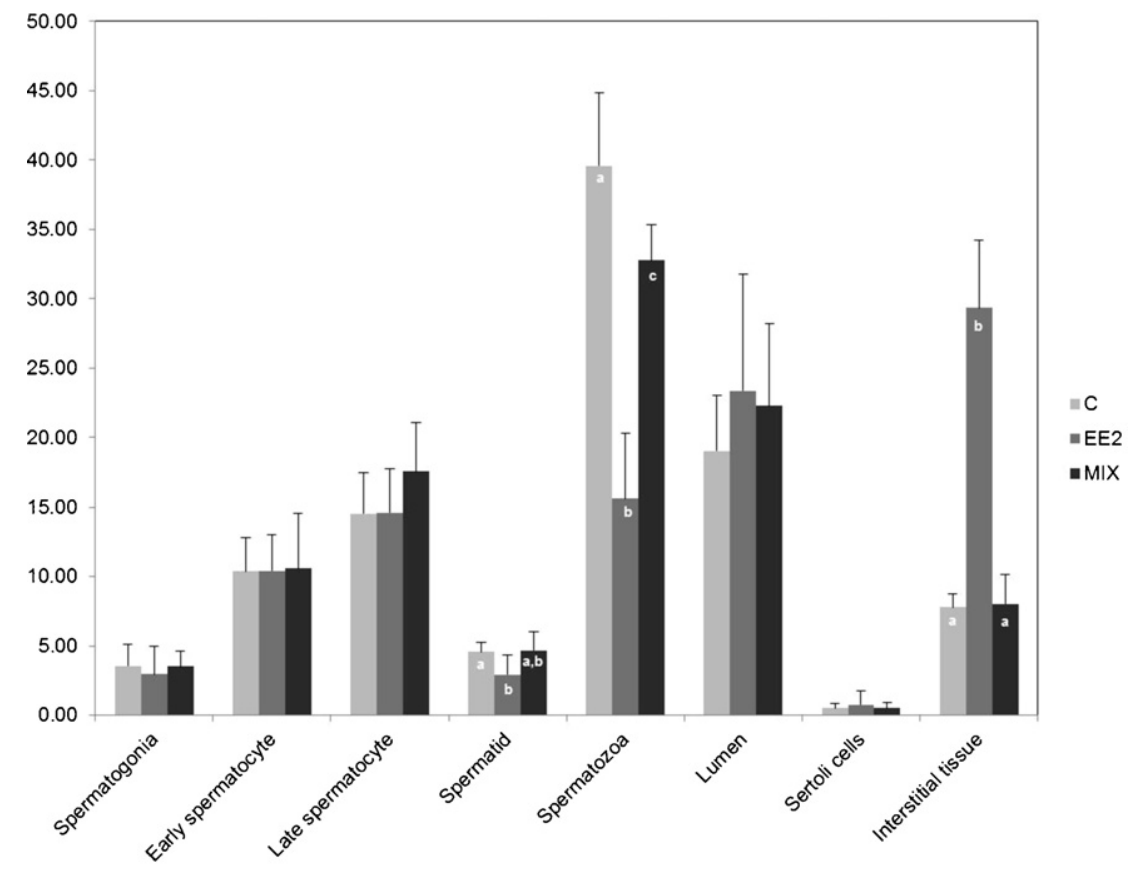

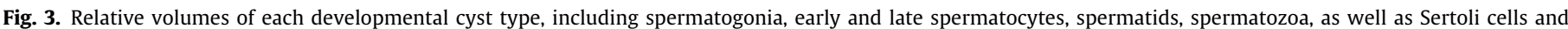

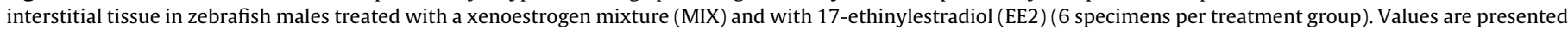

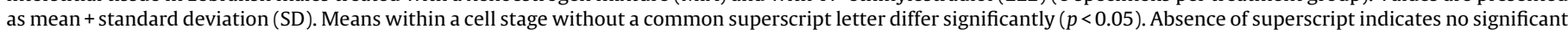
difference between treatments. 


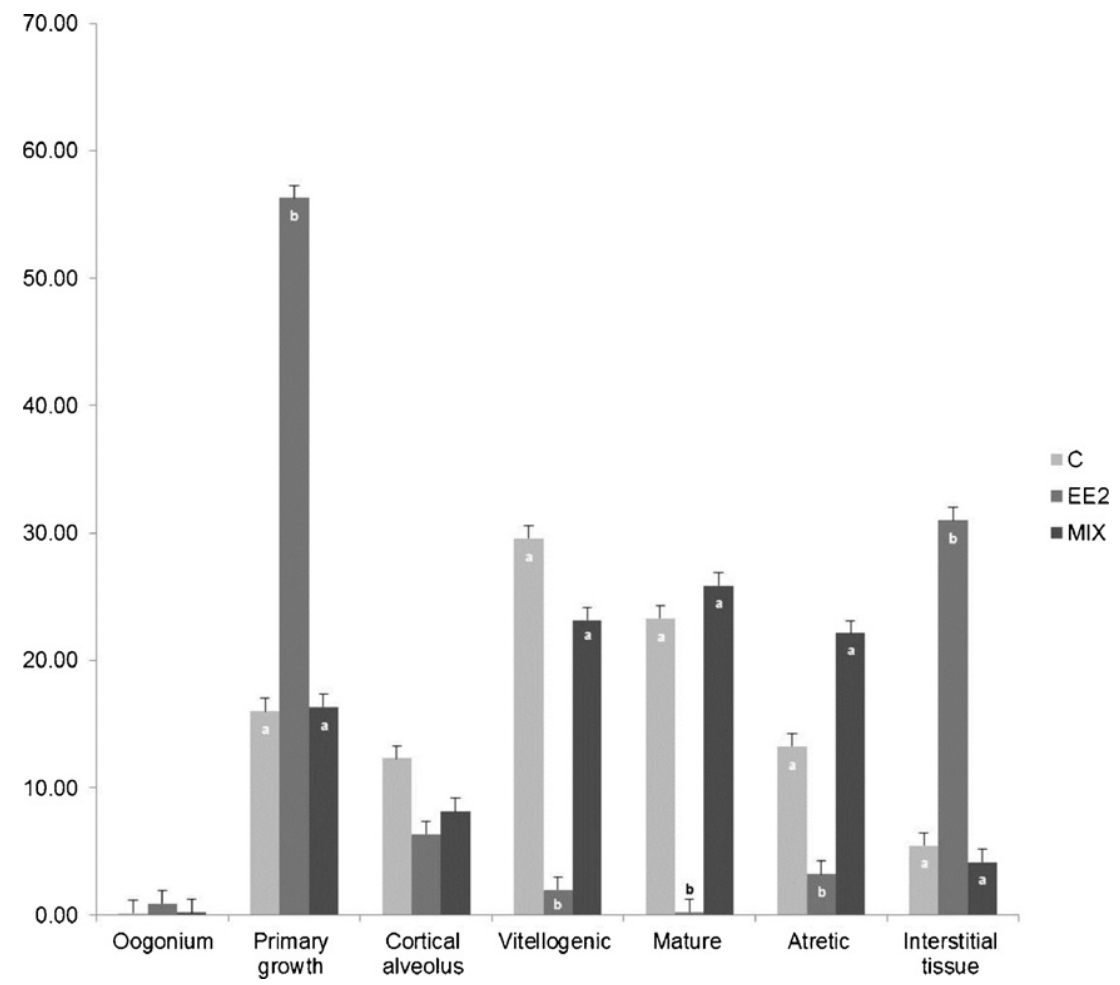

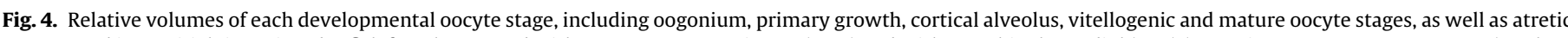

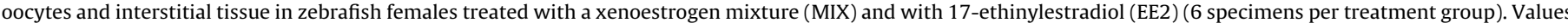

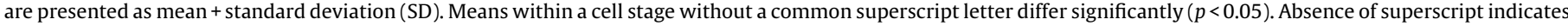
no significant difference between treatments.

absolute volumes of germ cells in fish gonads. Most studies on the effects of xenoestrogens on gonad histology have focused on single chemicals, regardless of the fact that ecosystems are impacted by low to high concentrations of different chemicals. This is the case of the Douro River estuary where Rocha et al. (2011) found a mixture of both natural and synthetic steroidal estrogens and non-steroidal synthetic estrogenic compounds. Under a sub-acute exposure, we evaluated detailed effects of a mixture of

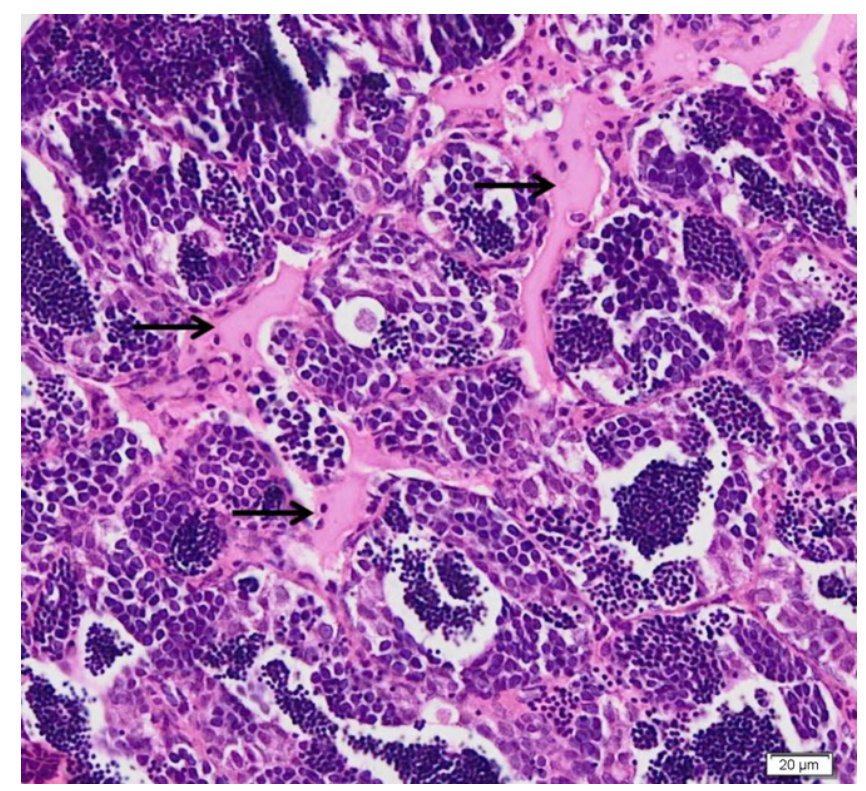

Fig. 5. Pathological alterations observed in testis of zebrafish treated with 17ethinylestradiol (EE2) (arrows - proteinaceous fluid). xenoestrogens, as observed in the cited study, in zebrafish gametogenesis. We applied a stereological approach never performed in previous studies that have tackled such effects.

\subsection{Effects on spermatogenesis}

Despite our histological examination showed on-going gametogenesis, once all germ cell types were present in gonads of both control and exposed animals, the fact is that significant disruptions were revealed. One major finding was that exposure to the xenoestrogen mixture caused disruption of gametogenesis in males only. Stereology revealed a decrease in relative volume of spermatozoa in fish exposed to the MIX and additionally to EE2, with the lowest value noticed in the latter group. The absolute volume of spermatozoa was, however, the same in the MIX and in the control group. These results highlight the importance of carrying out a complete (multi-level) stereological analysis in this type of studies, since the examination of the absolute volumes could not translate the fine gametogenesis dynamics. The analysis of the absolute volumes estimated for the testis also revealed that exposure to EE2 inhibited testicular growth. The reduction of the testicular volume of those fish was caused by a decrease of the total volume of all types of germ cells. The mechanism(s) behind the inhibition of testicular growth by estrogenic chemicals is(are) not yet clear. They could either act directly on the testis, inducing the local suppression of testicular androgen, or interfere at one or more levels in the hormonal cascade that regulate the maturation, ultimately inhibiting the spermatogenesis (Jobling et al., 1996). Another possible explanation is an effect on the Sertoli cells. A direct (or indirect) effect of estrogenic compounds on Sertoli cells is plausible since it was found that these cells express estrogen receptors (Legler et al., 2000; Andreassen et al., 2003). A severe effect on the cytology of Sertoli cells during spermatogenesis was found in eelpout (Zoarces viviparous) after 

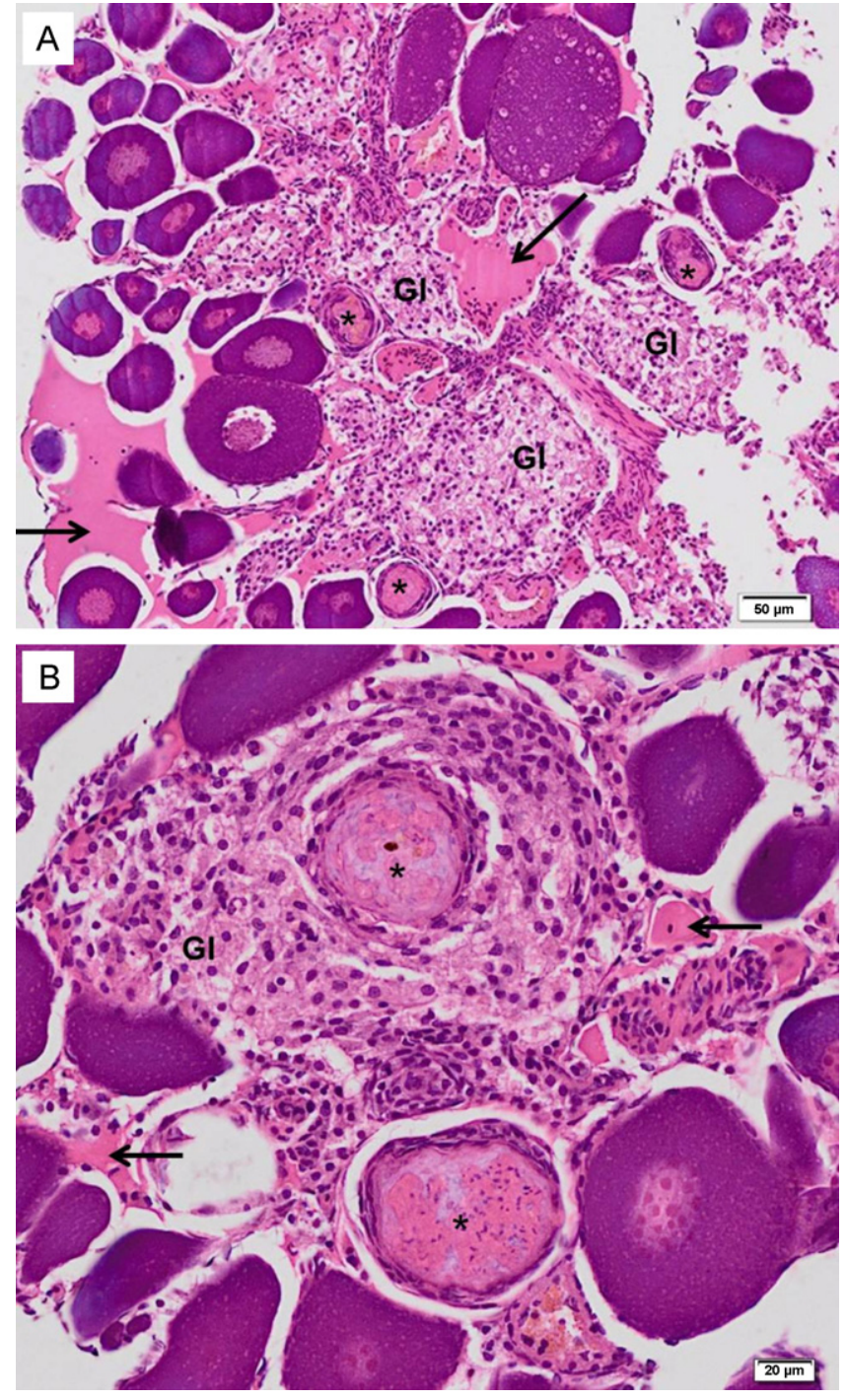

Fig. 6. Pathological alterations observed in zebrafish females treated with a 17ethinylestradiol (EE2). The ovary is mainly composed by follicles in the early stages of development. In the interstitial tissue is possible to observe within fibrotic tissue the existence of a pink proteinaceous fluid (arrows), granulomatous inflammation areas (GI) and nearby these suggestively mineralized structures (asterisk).

exogenous administration of E2 and 4-nonylphenol (Christiansen et al., 1998). In the eel, Anguilla anguilla, EE2 inhibited the development or caused degeneration of Sertoli cells, thus indicating that estrogens may affect the somatic components of the gonad first and the germ cells later (Colombo and Grandi, 1995). As in our work the Sertoli cell volumes were similar in all groups, we cannot suggest that those cells were strongly impacted. However, functional changes cannot be excluded and a disruption of the Sertoli cells could well impact on germ cell maturation; this event would help to explain the reduced sperm production noted in the MIX and EE2 groups. Regardless of the mechanism(s) involved, it is obvious that the MIX found in Douro River had negative effects on the testis structure of zebrafish, resulting in disturbance (decrease) of spermatogenesis.

When compared to EE2 the MIX had similar consequences on the testis, but to a lower extent, indicating that the MIX effects may have occurred via estrogenic signaling. The estrogenic effects of the MIX on zebrafish males were also demonstrated in a parallel study conducted by our group, which showed that the exposure to EE2 and MIX was physiologically active and induced vitellogenin mRNA in both treatment groups and in a similar range despite of the lower estrogenic potency of the MIX (Urbatzka et al., 2012). Actually, zebrafish is highly responsive to vitellogenin mRNA induction and this effect was observed in males exposed to $9.5 \mathrm{ng} / \mathrm{L}$ of EE2, a much lower concentration than the one used in our study (Lange et al., 2012). Some scientists pointed out, however, that biomarkers of estrogen exposure could be evoked by some "environmental estrogens" with antiandrogenic activity (Sohoni and Sumpter, 1998). Such activity was reported for two compounds of the MIX used herein, namely bisphenol A (BPA) (Paris et al., 2002; Sohoni and Sumpter, 1998; Sun et al., 2006) and 4-ter-octylphenol (Paris et al., 2002). Such actions, however, were obtained with in vitro and gene expression assays and the antiandrogenic activity was observed only at concentrations much higher than the ones used in our MIX. Moreover, links between altered gene expression patterns and physiological implications were not established, since no phenotype effect was recorded in those studies. However, some degree of an antiandrogenic effect of the MIX cannot be discarded, and more studies are needed to discover the physiological effects of the EDCs with antiandrogenic activity.

\subsection{Effects on oogenesis}

In females, no differences in either the relative or the absolute volumes of the ovary and of each different oocyte stage were found between the MIX and the control group. As hypothesized, and in line with what have been published for zebrafish (Lin and Janz, 2006; Van Den Belt et al., 2002; Weber et al., 2003), the ovary of the females exposed to EE2 had a higher relative volume of primary growth stage oocytes and a lower relative volume of vitellogenic and mature oocytes than the control group, thus showing that ovaries responded sensitively to exposure to xenoestrogens. As the ovary of the fish exposed to EE2 was the smallest, the absolute volume of the primary growth stage oocytes was similar in the various groups. This is of fundamental importance, meaning that the baseline pool of primary growth oocytes did not actually increase under EE2 exposure, but rather it stayed stable - estrogenic impacts were thus targeting the more mature stages. Again, these results highlight the need to look both for absolute and for relative volumes of the germ cells to really understand the morphofunctional changes occurring in the gonads - partial approaches can indeed promote misinterpretations.

One possible explanation for the different results obtained in males and females is that the estrogenic threshold for suppressing male gametogenesis is lower than that for females. Therefore, the xenoestrogens in the mixture (20.73 ng/L EE2-equivalents, Urbatzka et al., 2012) allowed for oogenesis to occur but suppressed spermatogenesis. At the higher estrogenic exposure (100 ng/L EE2) there was gametogenesis disruption in both males and females. In line with our conclusions, Hill and Janz (2003) conducted a partial life-cycle (2-60 dph) study with zebrafish concluding that low estrogen concentrations ( $1 \mathrm{ng} / \mathrm{L}$ nominal) affect only male gametogenesis, whereas disruption of female maturation require higher estrogen levels ( $100 \mathrm{ng} / \mathrm{L}$ nominal). This difference between the sexes could be linked to the distinctive nature of the hormonal regulation in male vs. female gametogenesis. Further studies are needed to confirm this hypothesis.

\subsection{Effects on biometric parameters}

Similar body weight, gonad weight and GSI were found in males of the MIX and the control group. These biometric parameters were lower for males exposed to EE2, in agreement with other studies where a GSI decrease was found in various adult male fish species experimentally exposed to chemicals with estrogenic activity (Gimeno et al., 1998; Jobling et al., 1996; Komen et al., 1989), including zebrafish (Van Den Belt et al., 2002). The absence of 
differences in GSI between males of the MIX and control groups, revealed that the use of the index alone was not, by itself, an appropriate proxy for evaluating the subtle spermatogenesis disturbances and highlighted the importance of using stereological microscopic techniques to study the EDC effects on gonads. Also in a recent study with zebrafish aimed at disclosing the qualitative and quantitative effects of sub-acute exposures to five distinct pharmaceuticals (also found in the Douro River) in the fish gonadal maturation dynamics, Madureira et al. (2011) found that the sensitivity of GSI to those substances did not correspond to gonad volume partitioning, which reinforces the idea that GSI does not always show the real toxicant effects of compounds on the fish gonads. The biometric parameters were lower for the EE2 female group when compared to the MIX and control groups. The lower GSI for EE2 is, probably, a result of a reduction in the ovary size due to the loss of mature germ cells. No effect of the xenoestrogens mixture was observed on females regarding body and gonad weights. The GSI value, however, was higher in the MIX group when compared to the other groups. As a result, similar to males, the female GSI after the exposure to the xenoestrogens mixture did not reflect the stereological results. In short, the GSI should not be a single endpoint to study xenoestrogens effects on fish gametogenesis.

\subsection{About the effects of single chemicals vs. mixtures}

Over the last decades, field and laboratory studies have shown induction of adverse effects in fish gonads under exposure to single xenoestrogens. Exposure of zebrafish to EE2 ( $\geq 1 \mathrm{ng} / \mathrm{L}$ nominal) has been reported to inhibit gametogenesis both in the early (Lin and Janz, 2006; Weber et al., 2003) and late life stages (Van Den Belt et al., 2002). Repression of gametogenesis was also observed in zebrafish exposed to nonylphenol ( $\geq 100 \mu \mathrm{g} / \mathrm{L}$ nominal) (Lin and Janz, 2006; Weber et al., 2003). A somewhat similar result was obtained in rainbow trout (Oncorhynchus mykiss) males in a study including EE2 $(\approx 1.8 \mathrm{ng} / \mathrm{L})$, nonylphenol and other alkylphenols, such as: 4-tert-octylphenol (4-t-OP, $\approx 38.5 \mu \mathrm{g} / \mathrm{L}$ ), nonylphenoxycarboxylic acid (NP1EC, $\approx 31.8 \mu \mathrm{g} / \mathrm{L}$ ) and nonylphenoldiethoxylate (NP2EO, $\approx 38.3 \mu \mathrm{g} / \mathrm{L}$ ) (Jobling et al., 1996). Gonadal disruption was also seen under estrone $(\mathrm{E} 1, \approx 31.8 \mathrm{ng} / \mathrm{L})$ and $17 \beta$-estradiol (E2, $>100 \mathrm{ng} / \mathrm{L}$ ) exposures in an experiment with fathead minnows (Pimephales promelas) (Panter et al., 1998). Lin and Janz (2006) determined the effects of exposure to binary mixtures of both EE2 and nonylphenol on gametogenesis of zebrafish, and they found that such exposure supressed the oogenesis in an additive way in females at $60 \mathrm{dph}$. Based on our results it is not possible to predict the way these chemicals interact with each other and this was beyond our scope. The noted disruption of spermatogenesis in our study could thus have been caused by additive and/or non-additive effects.

Exposure to MIX caused changes in zebrafish gametogenesis, especially in males. Local effects of reproduction toxicity attributed to xenoestrogens found in the Douro River were demonstrated before, such as the consistent presence of abnormal testis-ova in grey mullet (Mugil cephalus) males (Carrola et al., 2009; Ferreira et al., 2004). The effects of the xenoestrogens on the germ cell maturation as seen in our study were obtained with realistic environmental concentrations (Rocha et al., 2011), and it must be emphasized that these were even lower than the ones very recently reported also for the Douro estuary by Rocha et al. (2012). The authors concluded that anthropogenic pollution in the Douro estuary is a continuous process and that the EDCs were present in quantities that should be able to produce endocrine disruption under diverse conditions and in different species. The present study supports this idea and agrees with others that have found fish reproduction impairment at low xenoestrogen concentrations. The lowest observable effect concentration (LOEC) for effects on fecundity and fertility was found in zebrafish, where a lifelong exposure to $5 \mathrm{ng} / \mathrm{L}$ EE2 caused 56\% reduction in fecundity and complete population failure with no fertilization (Nash et al., 2004). The effects of EE2 at small concentrations in fish reproduction were also reported in other studies: (i) $0.1-15 \mathrm{ng} / \mathrm{L}$ can affect the normal sexual development and differentiation (Andersen et al., 2003; Metcalfe et al., 2001; Weber et al., 2003); (ii) 2-10 ng/L can affect fecundity (Länge et al., 2001; Scholz and Gutzeit, 2000; Van Den Belt et al., 2002); and (iii) 1-10 ng/L can reduce the fertilization success or the viability of embryos from exposed adults (Hill and Janz, 2003; Länge et al., 2001; Segner et al., 2003). Summarizing, the data support the notion that the concentrations of the chemicals with estrogenic activity found in the Douro River estuary are sufficient to impair fish gametogenesis, with yet not clear consequences to the fertility of fish inhabiting those waters.

This is one of the first studies on sub-acute effects of an environmentally relevant mixture of xenoestrogens in the gametogenesis kinetics of zebrafish using stereological tools, directed at relative and absolute volumes. Previous studies on estrogen exposure have used various techniques, such as vitellogenin detection and common histology. The latter mainly involved qualitative tissue analyses, resulting in descriptions of structural alterations (as detailed, e.g., by Segner et al., 2003). The application of stereology in this study allowed us to quantify, in an unbiased way, some of those gonad alterations, namely the relative volume occupied by the different germ cell types present in the gonads, leading to sound conclusions about estrogenic effects on gametogenesis. This stereological approach is also a very useful tool to study the impact of non-estrogenic compounds in zebrafish gonads (Madureira et al., 2011). As a result, it is our opinion that histologic effects on fish gonads as evaluated by stereology may be one of the most sensitive and relevant endpoints to look at in reproductive toxicology.

\subsection{Histopathological findings}

Pathological changes in testis exposed to EE2 and to the Douro River mixture were seen in our study. The alterations included presence of interstitial fibrosis and proteinaceous fluid. Increased interstitial fibrosis was earlier found after estrogenic exposure of adult male fish (Gray et al., 1999; Karels et al., 2003; Rasmussen et al., 2005). Rasmussen et al. (2005) demonstrated that an antiestrogen can abolish effects on the histology of the testis, proving that some effects are mediated by the estrogen receptor. Half of the males possessed proteinaceous fluid in both assay groups (EE2 and MIX); this kind of fluid is presumably a derivate from vitellogenin, the presence of which in the testis is usually linked to exposure to estrogenic substances (OECD, 2009). The proteinaceous fluid in the testis of fish exposed to the mixture relates well with the above proposal - i.e., that the xenoestrogen mixture effects were via estrogenic signaling.

Pathological changes of the ovaries were also present, appearing as follicular atresia, fibrosis, proteinaceous fluid presence and infiltration with macrophages. Ovarian follicle atresia was lower in fish exposed to EE2 than in fish exposed to the xenoestrogens mixture or in fish of the control group. This could be explained by the fact that ovaries of females of both control and MIX groups had more vitellogenic and mature follicles than the ones exposed to EE2. Follicles in an advanced maturity stage had a higher probability of becoming atretic therefore occupying higher volume in the ovary. Despite not having been unbiasedly quantified, increased ovarian follicle atresia was reported in studies where fish have been exposed to estrogens (Gray et al., 1999; Länge et al., 2001; Papoulias et al., 1999; Zillioux et al., 2001). All females exposed to the higher estrogenic stimulus (EE2) possessed granulomatous inflammation and proteinaceous fluid in the ovary and half of them had also mineralized structures. From all pathological alterations 
mentioned before only the presence of the proteinaceous fluid was found in fish exposed to the mixture ( 3 out of 6 ). Similarly, Schäfers et al. (2007) in a full life-cycle zebrafish exposure to EE2 saw fibrosis and infiltration with macrophages and other inflammatory cells in the ovary. Although the exact cause of the pathological changes observed in fish exposed to the MIX remains unknown, it could be logically argued that they are linked to the estrogen exposure and can adversely affect breeding.

\section{Conclusions}

Exposure of adult zebrafish to EE2 for 21 days caused disruption of gametogenesis in both sexes, with a decrease of the volumes of the more advanced maturation cell stages. We demonstrated that gametogenesis responded sensitively to exposure to xenoestrogens and therefore unbiased stereological parameters are valuable additional endpoints in experimental and ecotoxicological studies. One major outcome of this study was that the exposure to the MIX found in the Douro River estuary (a proxy for other similarly polluted ecosystems) disrupted gametogenesis only in males, by decreasing the volume of spermatozoa. How the mixture prompted these changes in males is not yet known, but the data from EE2 exposure essentially point to estrogenicity as the culprit, with increasing effects observed with icreasing estrogen level. However, other underlying mechanisms, such as anti-androgen activity, may also play a role. It should be emphasized that prior to this investigation very few studies have unbiasedly evaluated quantitative effects of mixtures of toxicants on the histology of gonads. The presence of estrogenic chemicals, their persistence and accumulation in the Douro River and other aquatic systems, together with the herein reported effects on fish gametogenesis, indicate that such local "estrogenic mixtures" can have severe consequences.

\section{Acknowledgments}

This work was financially supported by FEDER funds through the Competitiveness and Trade Expansion Program - COMPETE and by National Funds provided by Fundação para a Ciência e a Tecnologia - FCT, via the research project PTDC/MAR/70436/2006.

\section{References}

Andersen, L., Bengtsson, B.E., Björk, M., Gessbo, A., Holbech, H., Hylland, K., Norrgren, L., Pedersen, K.L., Lundgren, A., Petersen, G.I., Steinholz, A., Örn, S., 2000.Zebrafish for testing endocrine disrupting chemicals. TemaNord 555, Copenhagen.

Andersen, L., Holbech, H., Gessbo, A., Norrgren, L., Petersen, G.I., 2003. Effects of exposure to $17 \alpha$-ethinylestradiol during early development on sexual differentiation and induction of vitellogenin in zebrafish (Danio rerio). Comp. Biochem. Physiol. C Toxicol. Pharmacol. 134, 365-374.

Andreassen, T.K., Skjoedt, K., Anglade, I., Kah, O., Korsgaard, B., 2003. Molecular cloning, characterisation, and tissue distribution of oestrogen receptor alpha in eelpout (Zoarces viviparus). Gen. Comp. Endocrinol. 132, 356-368.

Ashfield, L.A., Pottinger, T.G., Sumpter, J.P., 1998. Exposure of female juvenile rainbow trout to alkylphenolic compounds results in modifications to growth and ovosomatic index. Environ. Toxicol. Chem. 17, 679-686.

Blázquez, M., Zanuy, S., Carrillo, M., Piferrer, F., 1998. Structural and functional effects of early exposure to estradiol- $17 \beta$ and $17 \alpha$-ethinylestradiol on the gonads of the gonochoristic teleost Dicentrarchus labrax. Fish Physiol. Biochem. 18, 37-47.

Carrola, J., Fontaínhas-Fernandes, A., Pardal, M., Castro, B., Rocha, E., 2009. Intersex ratio in grey mullets from the Mondego, Douro and Ave estuaries, Portugal preliminary data. In: 15th International Symposium on Pollutant Responses in Marine Organisms - PRIMO 15, Bordeaux (France), 17-20 of May, p. 326, Abstract book.

Christiansen, T., Korsgaard, B., Jespersen, Å., 1998. Effects of nonylphenol and 17ßoestradiol on vitellogenin synthesis, testicular structure and cytology in male eelpout Zoarces viviparus. J. Exp. Biol. 201, 179-192.

Colombo, G., Grandi, G., 1995. Sex differentiation in the European eel: histological analysis of the effects of sex steroids on the gonad. J. Fish Biol. 47, 394-413.

Depledge, M.H., Billinghurst, Z., 1999. Ecological significance of endocrine disruption in marine invertebrates. Mar. Pollut. Bull. 39, 32-38.
Drèze, V., Monod, G., Cravedi, J.P., Biagianti-Risbourg, S., Le Gac, F., 2000. Effects of 4-nonylphenol on sex differentiation and puberty in mosquitofish (Gambusia holbrooki). Ecotoxicology 9, 9-103.

Falconer, I.R., Chapman, H.F., Moore, M.R., Ranmuthugala, G., 2006. Endocrine disrupting compounds: a review of their challenge to sustainable and safe water supply and water reuse. Environ. Toxicol. 21, 181-191.

Ferreira, M., Antunes, P., Gil, O., Vale, C., Reis-Henriques, M.A., 2004. Organochlorine contaminants in Xounder (Platichthys Xesus) and mullet (Mugil cephalus) from Douro estuary, and their use as sentinel species for environment monitoring. Aquat. Toxicol. 69, 347-357.

Gimeno, S., Komen, H., Jobling, S., Sumpter, J., Bowmer, T., 1998. Demasculinization of sexually mature male common carp, Cyprinus carpio, exposed to 4-tertpentylphenol during spermatogenesis. Aquat. Toxicol. 43, 93-109.

Gray, M.A., Metcalfe, C.D., 1997. Induction of testis-ova in Japanese medaka (Oryzias latipes) exposed to p-nonylphenol. Environ. Toxicol. Chem. 16, 1082-1086.

Gray, M.A., Niimi, A.J., Metcalfe, C.D., 1999. Factors affecting the development of testis-ova in medaka. Oryzias latipes, exposed to octylphenol. Environ. Toxicol. Chem. 18, 1835-1842.

Gutendorf, B., Westendorf, J., 2001. Comparison of an array of in vitro assays for the assessment of the estrogenic potential of natural and synthetic estrogens, phytoestrogens and xenoestrogens. Toxicology 166, 79-89.

Hill, R.L., Janz, D.M., 2003. Developmental estrogenic exposure in zebrafish (Danio rerio): I. Effects on sex ratio and breeding success. Aquat. Toxicol. 63, 417-429.

Howard, C.V., Reed, M.G., 2005. Unbiased Stereology. Three-Dimensional Measurements in Microscopy, 2nd edition. Garland Science/Bios Scientific Publishers, Oxon and New York.

Hutchinson, T.H., Shillabeer, N., Winter, M.J., Pickford, D.B., 2006. Acute and chronic effects of carrier solvents in aquatic organisms: a critical review. Aquat. Toxicol. $76,69-92$

Jobling, S., Sheahan, D., Osborne, J.A., Matthiessen, P., Sumpter, J.P., 1996. Inhibition of testicular growth in rainbow trout (Oncorhynchus mykiss) exposed to estrogenic alkyl-phenolic chemicals. Environ. Toxicol. Chem. 15, 194-202.

Karels, A.A., Manning, S., Brouwer, T.H., Brouwer, M., 2003. Reproductive effects of estrogenic and antiestrogenic chemicals on sheepshead minnows (Cyprinodon variegatus). Environ. Toxicol. Chem. 22, 855-865.

Khan, I.A., Thomas, P., 1998. Estradiol-17beta and o,p'-DDT stimulate gonadotropin release in Atlantic croaker. Mar. Environ. Res. 46, 149-152.

Kolpin, D.W., Furlong, E.T., Meyer, M.T., Thurman, E.M., Zaugg, S.D., Barber, L.B. Buxton, H.T., 2002. Pharmaceuticals, hormones, and other organic wastewater contaminants in U.S. streams, 1999-2000: a national reconnaissance. Environ. Sci. Technol. 36, 1202-1211.

Komen, J., Lodder, P.A.J., Huskens, F., Richter, C.J.J., Huisman, E.A., 1989. Effects of oral administration of $17 \alpha$-methyltestosterone and $17 \beta$-estradiol on gonadal developmentin common carp, Cyprinus carpio. Aquaculture 78, 349-363.

Lange, A., Katsu, Y., Miyagawa, S., Ogino, Y., Urushitani, H., Kobayashi, T., Hirai, T. Shears, J.A., Nagae, M., Yamamoto, J., Ohnishi, Y., Oka, T., Tatarazako, N., Ohta, Y. Tyler, C.R., Iguchi, T., 2012. Comparative responsiveness to natural and synthetic estrogens of fish species commonly used in the laboratory and field monitoring. Aquat. Toxicol. 109, 250-258.

Länge, R., Hutchinson, T.H., Croudace, C.P., Siegmund, F., Schweinfurth, H., Hampe, P., Panter, G.H., Sumpter, J.P., 2001. Effects of the synthetic oestrogen 17aethinylestradiol on the life-cycle of the fathead minnow (Pimephales promelas). Environ. Contam. Toxicol. 20, 1216-1227.

Laws, S.C., Carey, S.A., Ferrell, J.M., Bodman, G.J., Cooper, R.L., 2000. Estrogenic activity of octylphenol, nonylphenol, bisphenol A and methoxychlor in rats. Toxicol. Sci. 54, 154-167.

Legler, J., Broekhof, J.L.M., Brouwer, A., Lanser, P.H., Murk, A.J., Van der Saag, P.T., Vethaak, A.D., Wester, P., Zivkovic, D., Van der Burg, B., 2000. A novel in vivo bioassay for (xeno-) estrogens using transgenic zebrafish. Environ. Sci. Technol. $34,4439-4444$.

Lin, L.L., Janz, D.M., 2006. Effects of binary mixtures of xenoestrogens on gonadal development and reproduction in zebrafish. Aquat. Toxicol. 80, 382-395.

Madureira, T.V., Rocha, M.J., Cruzeiro, C., Galante, M.H., Monteiro, R.A., Rocha, E., 2011. The toxicity potential of pharmaceuticals found in the Douro River estuary (Portugal): assessing impacts on gonadal maturation with a histopathological and stereological study of zebrafish ovary and testis after sub-acute exposures. Aquat. Toxicol. 105, 292-299.

Metcalfe, C.D., Metcalfe, T.L., Kiparissis, Y., Koenig, B.G., Khan, C., Hughes, R.J., Croley, T.R., March, R.E., Potter, T., 2001. Estrogenic potency of chemicals detected in sewage treatment plant effluents as determined by in vivo assays with Japanese medaka (Oryzias latipes). Environ. Toxicol. Chem. 20, 297-308.

Nash, J.P., Kime, D.E., Van der Ven, L.T.M., Wester, P.W., Brion, F., Maack, G., Stahlschmidt-Allner, P., Tyler, C.R., 2004. Long-term exposure to environmental concentrations of the pharmaceutical ethynylestradiol causes reproductive failure in fish. Environ. Health Perspect. 112, 1725-1733.

Panter, G.H., Thompson, R.S., Sumpter, J.P., 1998. Adverse reproductive effects in male fathead minnows (Pimephales promelas) exposed to environmentally relevant concentrations of the natural oestrogens, oestradiol and oestrone. Aquat. Toxicol. 42, 243-253.

Papoulias, D.M., Noltie, D.B., Tillitt, D.E., 1999. An in vivo model fish system to test chemical effects on sexual differentiation and development: exposure to ethinyl estradiol. Aquat. Toxicol. 48, 37-50.

Papoulias, D.M., Noltie, D.B., Tillitt, D.E., 2000. An in vivo model fish system to test chemical effects on sexual differentiation and development: exposure to ethinyl estradiol. Aquat. Toxicol. 48, 37-50. 
Paris, F., Balaguer, P., Terouanne, B., Servant, N., Lacoste, C., Cravedi, J.P., Nicolas, J.C., Sultan, C., 2002. Phenylphenols, biphenols, bisphenol-A and 4-tert-octylphenol exhibit alpha and beta estrogen activities and antiandrogen activity in reporter cell lines. Mol. Cell. Endocrinol. 193, 43-49.

Piferrer, F., Donaldson, E.M., 1992. The comparative effectiveness of the natural and a synthetic estrogen for the direct feminization of chinook salmon (Oncorhynchus tshawytscha). Aquaculture 106, 183-193.

Porte, C., Janer, G., Lorusso, L.C., Ortiz-Zarragoitia, M., Cajaraville, M.P., Fossi, M.C., Canesi, L., 2006. Endocrine disruptors in marine organisms: approaches and perspectives. Comp. Biochem. Physiol. C 143, 303-315

Preuss, T.G., Gehrhardt, J., Schirmer, K., Coors, A., Rubach, M., Russ, A., Jones, P.D., Giesy, J.P., Ratte, H.T., 2006. Nonylphenol isomers differ in estrogenic activity. Environ. Sci. Technol. 40, 5147-5153.

Rasmussen, T.H., Teh, S.J., Bjerregaard, P., Korsgaard, B., 2005. Anti-estrogen prevents xenoestrogen-induced testicular pathology of eelpout (Zoarces viviparus). Aquat. Toxicol. 72, 177-194.

Rocha, M.J., Ribeiro, C., Ribeiro, M., 2010. Development and optimization of a GC-MS method to evaluate relevant endocrine disrupters in environmental matrices estrogens and persistent pollutants. Int. J. Environ. Anal. Chem. 91, 1190-1204.

Rocha, M.J., Ribeiro, C., Ribeiro, M., 2011. Development and optimization of a GC-MS method to evaluate relevant endocrine disrupters in environmental matrices estrogens and persistent pollutants. Int. J. Environ. Anal. Chem. 19, 1191-1205.

Rocha, M.J., Cruzeiro, C., Ferreira, C., Rocha, E., 2012. Occurrence of endocrine disruptor compounds in the estuary of the Iberian Douro River and nearby Porto Coast (NW Portugal). Toxicol. Environ. 94, 252-261.

Scholz, S., Gutzeit, H.O., 2000. 17-alpha-ethinylestradiol affects reproduction, sexual differentiation and aromatase gene expression of the medaka (Oryzias latipes). Aquat. Toxicol. 50, 363-373.

Schäfers, C., Teigeler, M., Wenzel, A., Maack, G., Fenske, M., Segner, H., 2007. Concentration- and time-dependent effects of the synthetic estrogen. 17alpha ethinylestradiol, on reproductive capabilities of the zebrafish, Danio rerio. J. Toxicol. Environ. Health A 70, 768-779.

Segner, H., Caroll, K., Fenske, M., Janssen, C.R., Maack, G., Pascoe, D., Shäfers, C., Vandenbergh, G.F., Watts, M., Wenzel, A., 2003. Identification of endocrinedisrupting effects in aquatic vertebrates and invertebrates: report from the European IDEA project. Ecotoxicol. Environ. Saf. 54, 302-314.
Sohoni, P., Sumpter, J.P., 1998. Several environmental oestrogens are also antiandrogens. J. Endocrinol. 158, 327-339.

Sun, H., Xu, L.C., Chen, J.F., Song, L., Wang, X.R., 2006. Effect of bisphenol A tetrachlorobisphenol $\mathrm{A}$ and pentachlorophenol on the transcriptional activities of androgen receptor-mediated reporter gene. Food Chem. Toxicol. 44 (11), 1916-1921.

Tanaka, J., Grizzle, J.M., 2002. Effects of nonylphenol on the gonadal differentiation of the hermaphroditic fish, Rivulus marmoratus. Aquat. Toxicol. 57, $117-125$.

Urbatzka, R., Rocha, E., Reis, B., Cruzeiro, C., Monteiro, R.A.F., Rocha, M.J., 2012. Effects of ethinylestradiol and of an environmentally relevant mixture of xenoestrogens on steroidogenic gene expression and specific transcription factors in zebrafish. Environ. Pollut. 164, 28-35.

Van Den Belt, K., Wester, P.W., Van Der Ven, L.T.M., Verheyen, R., Witters, H 2002. Effects of ethinylestradiol on the reproductive physiology in zebrafish (Danio rerio): time dependency and reversibility. Environ. Toxicol. Chem. 21, 767-775.

Weber, L.P., Hill Jr., R.L., Janz, D.M., 2003. Developmental estrogenic exposure in zebrafish (Danio rerio): II. Histological evaluation of gametogenesis and organ toxicity. Aquat. Toxicol. 63, 431-446.

Ying, G.G., Kookana, R.S., Ru, Y.J., 2002. Occurrence and fate of hormone steroids in the environment. Environ. Int. 28, 545-551.

Zillioux, E.J., Johnson, I.C., Kiparissis, Y., Metcalfe, C.D., Wheat, J.V., Ward, S.G., Liu, H. 2001. The sheepshead minnow as an in vivo model for endocrine disruption in marine teleosts: a partial life-cycle test with 17alpha-ethinylestradiol. Environ. Toxicol. Chem. 20, 1968-1978.

\section{Further reading (Web references)}

OECD, 2009. OECD Guidance Document for the Diagnosis of EndocrineRelated Histopathology of Fish Gonads. Draft of January 7, 2009 http://www.oecd.org/dataoecd/33/27/42140701.pdf. 